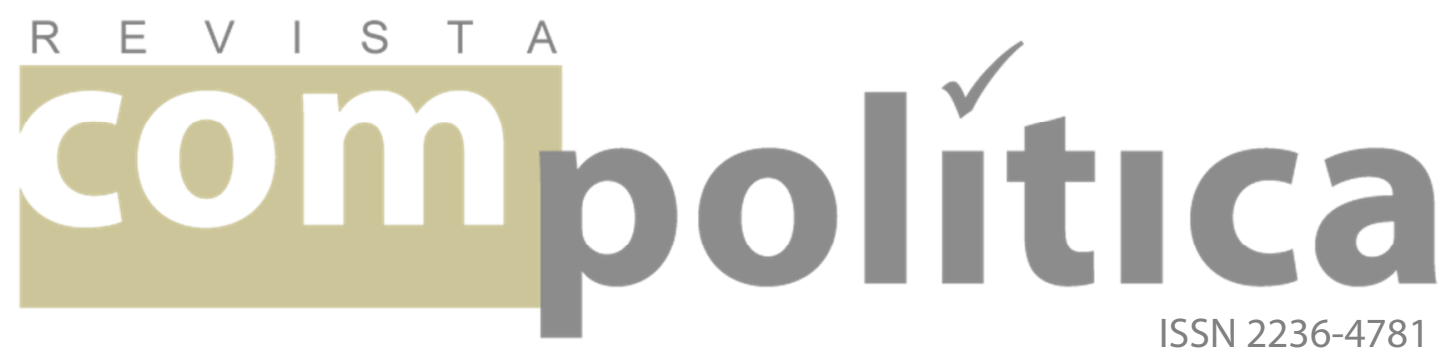

\title{
Facebook e accountability. um estudo de caso da fanpage da presidente Dilma Rousseff
}

\section{[Facebook and accountability: a case study on the president Dilma Rousseff's fanpage]}

\author{
PARMEGGIANI, Brenda \\ Doutoranda em Comunicação e Sociedade pela \\ Universidade de Brasília (UnB) \\ [PhD Candidate in Communication and Society from \\ Brasília University] \\ <brendaparmeg@gmail.com>
}

\section{RESUMO}

0 advento de novas tecnologias digitais cria expectativas sobre novas formas de comunicação, inclusive na política. Simultaneamente, a opinião pública clama por mecanismos de accountability. Assim, questiona-se: o Facebook pode ser utilizado como ferramenta de accountability? O estudo exige, primeiramente, uma discussão acerca de conceitoschave, como accountability, transparência e publicidade. além de um breve histórico sobre os sites de redes sociais (SRS). Com base nessas reflexões, conclui-se que o Facebook pode, sim, ser usado como instrumento de accountability, mas não o é por natureza. Logo, empreende-se uma análise de caso da fanpage da presidente Dilma Rousseff. Embora esteja claro o potencial das mídias digitais para desempenhar tal tarefa, constata-se que a página da presidente brasileira no SRS não realiza esse propósito.

Palavras-chave: Facebook; comunicação política; accountability.

\section{ABSTRACT}

The emergence of new digital technologies creates expectations about new forms of communication, including in politics and political communication. Including, the public clamors for accountability mechanisms nowadays. Therefore, we ask: Can Facebook be used as an accountability tool? The study, firstly, requires a discussion on key concepts such as accountability, transparency and publicity, as well as a brief history of the Social Networking Sites (SRS). Based on these considerations, we conclude that Facebook can indeed be used as an instrument of accountability, but it is not by nature. Thus, we develop an analysis of the case of Dilma Rousseff's fanpage. While the potential of digital media to perform such a task is clear, it appears that the page of the Brazilian president in SRS does not accomplish this purpose.

Keywords: Facebook; political communication; accountability. 


\section{Facebook e accountability: um estudo de caso da fanpage da presidente Dilma Rousseff}

PARMEGGIANI, Brenda

O surgimento de novas tecnologias carrega grandes expectativas pelo potencial que elas teriam de, no campo da Ciência Política e da Comunicação, aumentar a transparência, incrementar a comunicação entre representantes e representados, fornecer novas ferramentas de accountability, entre outras promessas. A accountability, em especial, ganha destaque por ser uma demanda da opinião pública que se desenvolva mecanismos institucionais para colocá-la em prática (SCHEDLER, 1999, p.347). Assim, propõe-se questionar: o Facebook, como parte do rol de novas tecnologias digitais, pode funcionar como uma ferramenta de accountability?

Embora o termo esteja em voga, sob a noção de uma preocupação com o controle e monitoramento do exercício do poder político, representa "um conceito inexplorado cujo significado permanece evasivo, cujos limites são vagos e cuja estrutura interna é confusa" (SCHEDLER, 1999, p.13). Assim, o presente artigo dispõe-se a discutir o conceito, reunindo olhares de diversos autores, no intuito de contribuir para uma definição, focada especialmente nos estudos que se localizam na intersecção dos campos da Ciência Política e da Comunicação. Além disso, preocupa a constatação de Paulino (2009, p.97), de que haveria um número reduzido de práticas de accountability no sistema político brasileiro. Assim, a proposta inclui 
um estudo de caso sobre o perfil da presidente do Brasil, Dilma Rousseff, no Facebook.

Cabe frisar, ainda, que o presente artigo não pretende abordar a discussão sobre uma possível crise da democracia representativa e da accountability $^{1}$, pois esses argumentos por formas de representação não-eleitoral não justificam $\mathrm{o}$ abandono de instrumentos de accountability que "permanecem sendo vetores incontornáveis da esperança de que os representados possam exercer algum tipo de controle sobre seus representantes" (MIGUEL, 2012, p.7).

Advoga-se pela importância da accountability por entendê-la como "principal mecanismo para impedir que os representantes, uma vez escolhidos, tornassem-se independentes dos representados" (MIGUEL, 2010, p.183-184). Sua importância ainda é reforçada pela possível resposta a três problemas políticos bastante atuais: "a separação entre governo e governados (...); a formação de uma elite política distanciada da massa da população; a ruptura do vínculo entre a vontade dos representados e dos representantes" (MIGUEL, 2005, p.26-27).

\section{Accountability: uma breve revisão do conceito}

Conforme bem aponta Miguel (2005, p.27), já se tornou "praticamente um lugar-comum observar que accountability não possui tradução precisa para o português (e para outras línguas

\footnotetext{
1 Para discussões acadêmicas sobre democracia representativa e sua paradoxalidade, e uma possível crise da accountability, consultar artigos do pesquisador Luís Felipe Miguel no repositório da Universidade de Brasília, disponíveis em:

<http://repositorio.unb.br/browse?type=author\&sort_by=1\&order=ASC\&rpp= $20 \&$ etal $=-1 \&$ value $=$ Miguel\%2C + Luis + Felipe\&offset $=20>$.
} 
neolatinas)". Bijos (2012, p.93) chama a atenção, ainda, para o fato de que o termo é utilizado em várias áreas do conhecimento científico, como Administração, Contabilidade e Economia, por exemplo. Em cada uma dessas áreas, a palavra carrega conceitos e aplicações diferentes. Para os fins deste artigo, portanto, o vocábulo não será traduzido e passará por uma revisão conceitual focada, por sua vez, na intersecção do campo da Ciência Política com o da Comunicação.

Semanticamente, de acordo com Schedler et al. (1999, p.4), a definição de accountability tem como base "dois pilares distintos: responsividade e enforcement", este no sentido de cumprimento e punição. O primeiro pilar refere-se à obrigação dos funcionários e agentes públicos de informar e explicar (com base em razões válidas e argumentação) o desempenho de sua função e suas decisões - o que, como e por que fazem da forma que fazem; enquanto o segundo diz respeito principalmente à capacidade de certas agências (accounting agencies) em fiscalizar e impor sanções aos que violaram seus deveres públicos (SCHEDLER, 1999, p.14-15).

Portanto, derivam do conceito de accountability três formas de prevenir e reparar o abuso do poder político, segundo Schedler (1999, p.14): a) pela submissão do poder às sanções - forma relacionada ao pilar de enforcement/punição; b) pela obrigação do exercício transparente das funções, no sentido de monitoramento público; e c) pelo dever de justificar os atos - ambas relacionadas ao pilar da responsividade.

Este termo merece atenção especial, pois uma série de autores (MIGUEL, 2005 e 2010; SCHEDLER, 1999; BIJOS, 2012; entre outros) na área da Ciência Política defende que é importante traçar uma distinção em relação à accountability. Segundo Schedler (1999, p.19), "enquanto a accountability obriga o poder [público/político] a entrar 
em um diálogo, a noção de responsividade permite que o poder permaneça em silêncio". Encontra-se aí a primeira diferença entre os conceitos: o caráter dialógico. Coleman $(2005$, p.190) vai ao encontro dessa ideia ao definir a accountability como interativa. Miguel (2005, p.27-28; 2010, p.184) e Bijos (2012, p.93), por sua vez, concordam entre si ao destacar a dimensão de sensibilidade e disposição dos representantes às vontades e preferências dos representados, essencial à responsividade. Para isso, de fato, não seria necessário obrigatoriamente um diálogo entre governantes e governados.

A accountability, por sua vez, trata-se de "um mecanismo institucional, exercido pelo povo e vinculado à existência de eleições competitivas periódicas" (MIGUEL, 2010, p.184). Esse mecanismo permite aos constituintes avaliar o seu desempenho, impor sanções aos governantes e reconduzir ao cargo os que cumprem bem sua função ou destituir aqueles que a desempenham de forma insatisfatória (MIGUEL, 2005, p.27-28 e 2010, p.184; BIJOS, 2012, p.93).

Mas a noção de accountability política não se resume apenas ao processo eleitoral, mesmo que este seja o seu ápice (MIGUEL, 2012, p.11-12). De acordo com Schedler (1999, p.23), diferentes formas de accountability demandam diferentes instrumentos (voto, meios de comunicação, etc.). A accountability pode, ainda, ser dividida de acordo com a relação de poder entre as partes: vertical e horizontal. Esta última remete à igualdade de poder; como não é o caso em estudo neste artigo (representados e presidente), focar-se-á na accountability vertical que, ao contrário, descreve uma relação entre desiguais, tanto de cima para baixo, quanto da base para o topo (SCHEDLER, 1999, p.23). Ou seja, refere-se "à necessidade que os representantes têm de prestar contas e submeter-se ao veredicto da população" (MIGUEL, 2005, p.27). 
Para alguns autores (MIGUEL, 2005, p.28 e 2010, p.185; BIJOS, 2012, p.94) a accountability merece destaque no campo da Ciência Política, em especial nos estudos sobre democracia, por dois motivos principais: pela necessidade de mecanismos de controle do povo sobre os representantes (como detentores do poder político), e pela vinculação entre as partes, uma vez que os governantes não devem tomar decisões conforme apenas o seu partido e precisam convencer seus eleitores que agiram da melhor forma posteriormente.

Pode-se dizer, pois, que "a ideia norteadora de accountability política é controlar o poder político", o que não significa, contudo, determinar como será o exercício desse poder político (SCHEDLER, 1999, p. 18-19). Por fim, a accountability não tem hora, nem lugar determinado: negativamente, acontece quando os representantes são "apanhados"; positivamente, representaria uma relação permanente de comunicação entre os governantes e o povo (COLEMAN, 2005, p.191). Trata-se, em suma, de um conceito amplo e relacionado a outros termos "vizinhos", tais como supervisão, vigilância, controle, monitoramento, punição (SCHEDLER et al., 1999, p.4-14).

Entre os termos relacionados à accountability, merecem destaque transparência e publicidade. Não se tratam apenas de "vizinhos", mas podem ser encarados como condições para sua legitimação. É por isso que as próximas duas subseções dedicar-se-ão a trabalhá-los.

\subsection{Accountability e transparência: o conceito e suas relações}

Para Schedler (1999, p.20), a accountability, principalmente no que se refere ao pilar da responsividade, "tem o objetivo de criar transparência”. O’Neill (2006, p.76), por sua vez, afirma que há um 
consenso "em ver a transparência como indispensável para a accountability e boa governança" dos representantes. O fato é que a transparência se tornou um elemento padrão da governança (O'NEILL, 2006, p.75) e, consequentemente, importante para melhor compreender a accountability.

De maneira geral, transparência pode ser entendida como um método para prevenir abusos de poder e corrupção e de governança inteligível e acessível ao povo (HOOD, 2006, p.5). Um governo transparente, defende Hood (2006, p.5), denota regras fixas e publicadas, baseadas em informações e procedimentos acessíveis ao público.

Sua principal função, de acordo com o'Neill (2006, p.76), é "disciplinar instituições e seus integrantes levando a público as informações sobre sua performance". Emerge dessa definição, portanto, outro termo chave para a compreensão da accountability: a publicidade, no sentido de tornar algo público, levar uma informação ao conhecimento público.

\subsection{Accontability e publicidade: o dever de tornar público}

Schedler (1999, p.21) é paradigmático ao afirmar que "accountability democrática deve ser pública", pois sem ela resta apenas uma caricatura de accountability. Já o pesquisador Stephen Coleman (2005, p.190) advoga que normas de accountability exigem interesses e ações públicos. Nesse caso, o termo não se refere apenas ao público como povo, como forma de sociabilidade, mas principalmente ao verbo publicar, a tornar algo de conhecimento público. 
Publicidade pública ou publicidade de utilidade pública é definida como aquela que tem por objetivo informar, orientar, avisar, prevenir ou alertar a população ou segmento da população para adotar comportamentos que lhe tragam benefícios sociais reais, visando melhorar a sua qualidade de vida (DUARTE \& VERAS, 2006 apud PRADO, 2009, p.196)

Por fim, uma república diferencia-se de regimes autoritários justamente pelo controle público do poder e pela formação de uma opinião pública (BOBBIO, 2005, p.28). A publicidade representa uma importante ferramenta da accountability, promovendo, por exemplo, "a destruição da reputação através da exposição pública" (SCHEDLER, 1999, p.16). Logo, os meios de comunicação e as associações civis são accounting agencies fundamentais para a desaprovação pública, pois usam formas discursivas de contestação e constrangimento (SCHEDLER, 1999, p.18).

\section{Facebook e accountability: possíveis relações na era digital}

De maneira geral, uma rede social pode ser entendida como um conjunto formado por dois elementos básicos: atores (pessoas, instituições ou grupos; os nós da rede) e as suas conexões (RECUERO, 2011, p.6). Segundo Recuero (2011, p.14), a noção de rede social no campo científico foi utilizada pela primeira vez como parte do trabalho do matemático Leonard Euler. As redes sociais não são, assim, um conceito novo. Contudo, o advento da comunicação mediada por computadores amplificou a capacidade de conexão, criando-se as redes sociais mediadas por computadores (RECUERO, 2011, p.15).

O sociólogo Manuel Castells (2007, p.33) também admite a já longa existência das redes sociais complexas e ressalta que, com os recentes avanços tecnológicos - em especial, os novos meios -, elas 
destacaram-se como forma dominante de organização social: "As pessoas organizam-se cada vez mais, não só em redes sociais como em redes sociais ligadas por computador". Lançado em 2004, o Facebook - site de rede social (SRS) que compõe o objeto de estudo deste artigo - é um sistema criado por Mark Zuckerberg.

\begin{abstract}
O Facebook funciona através de perfis e comunidades. (...) O sistema é muitas vezes percebido como mais privado que outros sites de redes sociais, pois apenas usuários que fazem parte da mesma rede podem ver o perfil uns dos outros. Outra inovação significativa do Facebook foi o fato de permitir que usuários pudessem criar aplicativos para o sistema. (RECUERO, 2011, p.86)
\end{abstract}

O Brasil possui cerca de 76 milhões de usuários no Facebook, dos quais 47 milhões acessam diariamente (GOMES, 2013). 0 total representa mais de um terço da população brasileira e mais de $80 \%$ dos usuários de internet no país (CONGO, 2013).

Segundo Danah Boyd e Nicole Ellison (2007, p.2), os SRS são sistemas que permitem: 1) a construção de uma persona através de um perfil ou página pessoal; 2) a interação pelos comentários publicados; e 3) a exposição pública da rede social de cada ator/usuário em sua lista de amigos. Cabe ressaltar, ainda, que os usuários do Facebook podem participar de grupos - sejam públicos ou privados -, normalmente baseados no interesse de seus membros (um determinado seriado de TV ou movimento político, por exemplo) ou em uma pessoa (personalidades de diversas áreas, inclusive política, como Barack Obama ou Dilma Rousseff, estudo de caso deste artigo), onde as pessoas discutem uma gama de temas e questões (SEEMAAN ET AL., 2014, p.5). Como perfis públicos, os usuários podem receber atualizações do(s) grupo(s) ou fanpage(s) em que participam no seu feed de notícias. 


\title{
2.1 O Facebook pode funcionar como uma ferramenta de accountability?
}

Chega-se, pois, a uma das questões centrais desta pesquisa: o Facebook pode então ser usado como uma ferramenta de accountability?

Coleman (2005, p.191) inclina-se positivamente a essa questão uma vez que concebe a accountability "como um processo interativo e possível através dos meios digitais de comunicação". Bertot et al. (2010, p.266) segue a mesma tendência quando sugere que as TICs oferecem novos caminhos, fornecendo amplo acesso a conteúdos e interações, ambos gerados a partir da interação social dos usuários por meio das mídias sociais. E o potencial dessa nova tecnologia não se esgota aí, na opinião dos autores:

\begin{abstract}
As mídias sociais têm quatro grandes vantagens potenciais: colaboração, participação, capacitação e tempo. São colaborativas e participativas, por sua própria natureza, já que são definidas pela interação social. Elas fornecem aos usuários a capacidade de se conectar e formar comunidades para socializar, compartilhar informações, ou alcançar um objetivo ou interesse comum. As mídias sociais podem capacitar os seus usuários, pois oferecem uma plataforma de discussão. Elas permitem que qualquer pessoa com acesso à Internet publique ou difunda informações a um baixo custo ou até gratuitamente, democratizando efetivamente a mídia (BERTOT et al., 2010, p. 266).
\end{abstract}

O sucesso das iniciativas políticas, como a accountability, quando desenvolvidas com recursos das TICs, dependerá, segundo Bertot et al. (2010, p.266), de fatores como: implantação, educação, aceitação entre os cidadãos e cultura, entre outros. Por outro lado, os autores confiam no caráter transformador das mídias sociais, em particular no que toca à transparência dos governos e ao combate à corrupção, por meio da combinação de vontade política e tecnologia (BERTOT et al., 2010, p.269). Coleman (2005, p.180) defende que as mídias digitais 
têm potencial para diminuir a importância da velha dicotomia emissor-receptor/produtor-consumidor.

$\mathrm{Na}$ prática, a pesquisa Pew Internet and American Life Project, desenvolvida pelo Pew Research Center (2014), revelou aumento na utilização da Internet e das chamadas mídias sociais para a atividade política. Entre os entrevistados, 25\% disseram que se tornaram mais envolvidos politicamente influenciados por informações em seus feeds de notícias, enquanto $16 \%$ admitiram que mudaram de opinião sobre uma questão política depois de conversar com amigos ou ler posts sobre o assunto nos SRS (PEW RESEARCH CENTER, 2014, p.3). Ainda, 36\% dos participantes consideraram que os SRS são "muito importantes" ou, pelo menos, "um pouco importantes" para manterem-se informados sobre notícias políticas (PEW RESEARCH CENTER, 2014, p.7).

É preciso apontar, contudo, que isso significa que a maioria considerável de usuários não considera os SRS muito importantes ou até os vê como nada importantes para essas atividades políticas (PEW RESEARCH CENTER, 2014, p.7). A grande maioria (84\%) disse que postou pouco $(63 \%)$ ou nada $(21 \%)$ relacionado à política em suas recentes atualizações de status, comentários e links (PEW RESEARCH CENTER, 2014, p.8). Apenas 6\% dos usuários afirmaram que a maior parte ou a totalidade do que recentemente postaram em sites de redes sociais está relacionada com política, enquanto outros $10 \%$ disseram que alguns de seus posts foram sobre política (PEW RESEARCH CENTER, 2014, p.11).

Embora ainda considerem cedo para medir o impacto das TICs nas iniciativas políticas, os autores defendem haver indícios de que podem ajudar a promover a transparência e combater corrupção por cumprirem as seguintes tarefas: 
a) fornecer informações sobre as regras do governo e os direitos dos cidadãos; b) fornecer informações sobre as decisões e ações do governo; c) promover o monitoramento das ações e gastos do governo; d) divulgar informações sobre o desempenho do governo; e) abrir processos governamentais, como registros de terra, os pedidos de certificados e status de pagamentos de impostos; f) identificar os funcionários eleitos e funcionários públicos sob investigação por corrupção e atividades fraudulentas; e g) divulgar ativos e investimentos de funcionários eleitos e funcionários públicos (BERTOT et al., 2010, p.267).

Uma vez que os autores no campo da Ciência Política afirmam que a accountability é caracterizada pelo monitoramento e justificativa das decisões tomadas por agentes públicos e pela punição quando o desempenho é considerado insatisfatório, os itens $b, c$ e $d$ têm relação direta com o conceito e sua prática. E se as TICs, neste caso o Facebook, podem "fornecer informações sobre as decisões e ações do governo; promover o monitoramento das ações e gastos do governo; [e] divulgar informações sobre o desempenho do governo" (BERTOT et al., 2010, p.267), elas tornam-se ferramentas de accountability.

Dessa forma, o Facebook também pode atender aos dois pilares da accountability, conforme Schedler (1999, p.4): atende à responsividade, pois oferece aos agentes públicos uma plataforma para informar e explicar publicamente seu desempenho e suas decisões; e atende ao enforcement/punição, já que, como meio de comunicação, pode levar "[à] destruição da reputação através da exposição pública" (SCHEDLER, 1999, p.16). Há casos no Brasil em que publicações no Facebook influenciaram diretamente e negativamente a reputação de uma pessoa ${ }^{2}$. Conclui-se, pois, que o Facebook pode funcionar como uma ferramenta de accountability - desde que seja usado politicamente para isso.

\footnotetext{
${ }^{2}$ Apenas como ilustração, pode-se retomar o caso da dona de casa no Rio de Janeiro que teve sua foto associada a uma sequestradora de crianças e, por isso, foi linchada no bairro onde morava. Embora seja um caso extremo e com informações falsas, pois a mulher não era a sequestradora citada na denúncia, ele demonstra como publicações no Facebook podem afetar a reputação publicamente.
} 


\section{O Facebook como ferramenta de accountability: uma análise da fanpage de Dilma Rousseff}

Antes de entrar na análise propriamente dita do estudo de caso proposto neste artigo, é preciso estabelecer que, apesar de se ter chegado à conclusão de que o Facebook pode ser um instrumento de accountability, o perfil da presidente Dilma Rousseff será analisado sem perder de vista que os SRS têm suas limitações, estas impostas pelo software em si (KLASTRUP, 2010, p.4). Logo, não se pode esperar que os usuários desenvolvam atividades que não estão dentro do leque de possibilidades oferecidas pela ferramenta - como curtir, compartilhar e comentar publicações ou, ainda, fazer seus próprios posts; de certa forma, o desempenho do usuário fica condicionado (KLASTRUP, 2010, p.4). Mesmo assim, conforme foi discutido na seção anterior, acredita-se que o Facebook pode servir como ferramenta de accountability, dentro dos seus limites.

Para os fins desta pesquisa, o perfil da presidente do Brasil no Facebook foi acompanhado ao longo dos primeiros seis meses deste ano. Como era importante para a análise um período de tempo mais longo - o primeiro semestre de 2014 -, mas o material gerado seria muito extenso se fossem consideradas todas as publicações, optou-se por levar em consideração a primeira semana de cada mês como um recorte para a coleta de números referentes aos posts e a observação do conteúdo publicado.

A página existe desde 2011 e é assinada por uma equipe que produz o conteúdo e o publica. Visualmente, trata-se de um perfil bem produzido. É importante ressaltar que a página está associada ao site 
da presidente, administrado, por sua vez, pelo partido (PT). O número de seguidores é um aspecto que merece destaque: de janeiro a junho, cresceu de 170 mil para 604 mil, somando mais de 400 mil novos usuários que passaram a receber as publicações da presidente em seu feed de notícias. De acordo com a empresa de pesquisa Social Bakers (2014), no entanto, a página ocupa apenas o 9o lugar no ranking de personalidades políticas brasileiras em junho, atrás do ex-presidente Lula $\left(5^{\circ}\right)$, do deputado federal Romário $\left(2^{\circ}\right)$ e do também deputado federal Marco Feliciano (1ํ), por exemplo. Apesar de estar atrás dos demais candidatos à presidência - Aécio Neves (6º) e Eduardo Campos (4º) - (SOCIAL BAKERS, 2014), o número de seguidores de Dilma Rousseff apresentou um significativo aumento no período analisado: mais de 200\%. É preciso apontar, ainda, que o perfil é público, logo, não é preciso “curti-lo" para acessá-lo; a diferença é que o usuário que curtiu a página recebe as atualizações em seu feed de notícias, enquanto os demais devem acessá-la para ver o conteúdo.

Além disso, pelo formato do próprio Facebook, ao apertar o botão “curtir" o usuário não está apenas “assinando" aquele conteúdo, contratando o recebimento das atualizações no seu feed de notícias; a ação de "curtir" é carregada de uma noção de endosso, de apoio à personalidade dona daquele perfil, neste caso a presidente. Assim, o mais provável é que os mais de 600 mil seguidores da página sejam também parte do eleitorado de Dilma Rousseff. Dessa forma, é possível afirmar que sua avaliação [dessas mais de 600 mil seguidores] sobre o desempenho da representante é satisfatória, logo é provável que a premiem nas próximas eleições com seu voto, em vez de puni-la ao votar em outro candidato e tentar destituí-la do cargo. 
O que se nota é uma dinâmica semelhante à de fã-celebridade: existe uma admiração dos seguidores - que curtem a página para acompanhar a presidente. Os comentários, em sua maioria, são mensagens de apoio, agradecimento e incentivo, conteúdo muito próximo ao fanpost ${ }^{3}$. Portanto, não se percebe o exercício do segundo pilar da accountability (SCHEDLER, 1999, p.14-15), no sentido de enforcement/punição. Os usuários dificilmente cobram a presidente sobre assuntos de interesse público ou adotam a postura ambivalente, da qual tratam Barros e Bernardes (2009, p.178): ao mesmo tempo em que respeitam e submetem-se à autoridade das instituições públicas, protestam sobre informações incompletas ou até não publicadas. Isso não acontece entre o público ativo no perfil da presidente no Facebook: em meio aos milhares de comentários abrangidos na análise - foram cerca de três mil por mês pouquíssimas exceções representavam esse papel questionador e/ou de oposição. No que tange à reputação da presidente, já que os teóricos consideram a possibilidade de "destruição da reputação através da exposição pública" (SCHEDLER, 1999, p.16) um dos principais instrumentos desse pilar da accountability, os usuários agem no sentido contrário, exaltando Dilma Rousseff e ajudando a consolidar uma boa reputação.

Em relação ao conteúdo, para fins de análise, foram estabelecidas sete categorias, conforme o quadro abaixo.

Quadro 1: Categorias de análise dos temas dos conteúdos publicados

\begin{tabular}{l|l}
\hline Agenda & $\begin{array}{l}\text { Eventos, encontros com autoridades, compromissos relacionados } \grave{a} \\
\text { agenda presidencial; }\end{array}$
\end{tabular}

\footnotetext{
${ }^{3}$ Considera-se fanpost uma opinião emitida ou um comentário cujo teor seja predominantemente emocional em relação a um programa de TV ou celebridade, por exemplo, baseado apenas no gosto do usuário (PARMEGGIANI, 2013).
} 


\begin{tabular}{l|l}
$\begin{array}{l}\text { Copa do Mundo } \\
\text { eleitoral }\end{array}$ & $\begin{array}{l}\text { Qualquer conteúdo relativo à Copa do Mundo no Brasil; } \\
\text { Embora não estivesse oficialmente em período de campanha, } \\
\text { como a presidente já havia se declarado candidata nas } \\
\text { próximas eleições, conteúdos relativos ao partido político de } \\
\text { cunho eleitoral e outros sobre comícios e atividades de } \\
\text { campanha; }\end{array}$ \\
$\begin{array}{l}\text { Programas de } \\
\text { governo }\end{array}$ & $\begin{array}{l}\text { Números e outras informações sobre programas de governo, } \\
\text { como "Luz para todos" ou "Bolsa Família", por exemplo; }\end{array}$ \\
$\begin{array}{l}\text { Pessoal / } \\
\text { Popularidade }\end{array}$ & $\begin{array}{l}\text { Conteúdos relativos à popularidade da presidente (como } \\
\text { número de curtidas em sua página) e ao seu lado pessoal; }\end{array}$ \\
$\begin{array}{l}\text { Bom dia / } \\
\text { Entretenimento }\end{array}$ & $\begin{array}{l}\text { Publicações de cunho relacionado ao entretenimento, como } \\
\text { saudações de "bom dia" da presidente ao seu público no } \\
\text { Facebook com vídeo de música; }\end{array}$ \\
Outros & $\begin{array}{l}\text { Notícias veiculadas em meios de comunicação (jornais, } \\
\text { emissoras de TV etc.), informações de interesse público, } \\
\text { entre outros conteúdos não contemplados pelas categorias } \\
\text { acima. }\end{array}$ \\
\hline
\end{tabular}

Fonte: análise da pesquisadora

Além disso, o formato do conteúdo também foi alvo de análise. Assim, foram designados cinco tipos: card - do jargão publicitário, trata-se de uma foto editada, com texto aplicado sobre ela -, vídeo, foto da presidente - imagem sem edição explícita, focada especialmente em Dilma Rousseff -, foto do público - imagem sem edição explícita, proveniente de arquivo pessoal, do público em geral ou pessoas comuns, às vezes acompanhadas da presidente, mas captadas por fotógrafos amadores - e link - para outros sites, para notícias etc.

No total, foram analisados 43 posts publicados na primeira semana de cada mês do primeiro semestre de 2014. 
Quadro 2: Temas dos conteúdos publicados no perfil de Dilma Rousseff no Facebook

\begin{tabular}{l|llllll}
\hline Mês & Copa & $\begin{array}{l}\text { Campanha } \\
\text { eleitoral }\end{array}$ & $\begin{array}{l}\text { Programa } \\
\text { de } \\
\text { governo }\end{array}$ & $\begin{array}{l}\text { Pessoal/ } \\
\text { Popularidade }\end{array}$ & $\begin{array}{l}\text { Bom dia / } \\
\text { Entretenimento }\end{array}$ & Outros \\
\hline Jan & 0 & 0 & 3 & 3 & 1 & 1 \\
Fev & 1 & 1 & 0 & 0 & 3 & 2 \\
Mar & 1 & 0 & 1 & 2 & 5 & 2 \\
Abr & 1 & 3 & 2 & 6 & 1 & 1 \\
Mai & 0 & 1 & 0 & 2 & 3 & 1 \\
\hline Jun & 1 & 0 & 0 & 0 & & 1
\end{tabular}

Fonte: análise com informações de http://www.facebook.com/SiteDilmaRousseff

Nota-se que a ênfase das publicações não está voltada para o cunho informativo, mas sim na figura da presidente - quase que a alçando à condição de celebridade - e no entretenimento, através de clipes de música popular brasileira no Youtube. Essa tendência de conteúdo denota que a função da página no Facebook é muito mais de relacionamento do que de informação e explicação das medidas e decisões do poder Executivo. Chama a atenção, ainda, o fato de a página não divulgar conteúdos relativos à agenda presidencial, tema comum nas publicações tanto no Facebook quanto no Twitter de outros representantes.

Levando-se em consideração a discussão realizada principalmente na seção 2 deste artigo, baseada em diversos autores na intersecção dos campos da Ciência Política e da Comunicação (MIGUEL, 2005, 2010 e 2012; BIJOS, 2012; COLEMAN, 2005; SCHEDLER ET AL., 1999), O conteúdo publicado não configura a página da presidente no Facebook como uma ferramenta de accountability. De fato, Dilma Rousseff e sua equipe não utilizam o espaço para praticar o pilar da 
responsividade, informando de suas decisões e explicando-as (SCHEDLER, 1999, p.14-15).

Quadro 3: Formato dos conteúdos publicados no perfil de Dilma Rousseff no $F B$

\begin{tabular}{l|lllll}
\hline Mês & Card & Vídeo & $\begin{array}{l}\text { Foto da } \\
\text { presidente }\end{array}$ & $\begin{array}{l}\text { Foto } \\
\text { público }\end{array}$ & do Link \\
\hline Jan & 6 & 1 & 1 & 0 & 0 \\
Fev & 2 & 4 & 1 & 0 & 0 \\
Mar & 6 & 3 & 0 & 0 & 0 \\
Abr & 8 & 2 & 4 & 0 & 0 \\
Mai & 1 & 3 & 1 & 0 & 1 \\
Jun & 1 & 1 & 0 & 2 & 1 \\
\hline
\end{tabular}

Fonte: análise com informações de http://www.facebook.com/SiteDilmaRousseff

Os formatos adotados demonstram preocupação em produzir um conteúdo atraente aos usuários, com ênfase nos cards e vídeos, largamente utilizados no âmbito da Internet. Apesar de visualmente muito bem produzido, não se nota um esforço voltado à interatividade $^{4}$. Conforme Barros e Bernardes (2009, p.178), os veículos de Comunicação Pública, como é a página da presidente no Facebook, deveriam incentivar a participação democrática dos usuários. No entanto, no período analisado, não se verifica esse incentivo. Em nenhuma publicação, constatou-se interação de fato, seja entre pares ou entre os usuários e a equipe que gerencia o perfil.

4 Cabe frisar que essa constatação refere-se ao período analisado, pois, posteriormente, a título de curiosidade, a pesquisadora continuou acessando a página e percebeu que houve algumas tentativas de promover a interatividade com os usuários. Um exemplo disso é a "rousselfie": os usuários foram convidados a enviar fotos do estilo "selfie" com Dilma e as imagens foram publicadas no perfil da presidente no Facebook. O sucesso dessas iniciativas não se pode medir, uma vez que elas não se enquadraram no período de análise proposto para o presente artigo. 
As atividades reproduzem o modelo produtor-consumidor: enquanto Dilma e sua equipe apenas emitem mensagens, os usuários restringem-se a consumir o conteúdo publicado, mesmo que curtam, compartilhem e comentem, geralmente o fazem de forma acrítica. Ignora-se, assim, o potencial interativo das mídias digitais frisado por Coleman $(2005$, p.180) e mantendo-se a lógica produtorconsumidor. Logo, o perfil da presidente no Facebook não cumpre uma das premissas da accountability que é o estabelecimento de um diálogo (SCHEDLER, 1999, p.19), de interatividade (COLEMAN, 2005, p.190).

\section{Considerações finais}

Embora se tenha concluído que o Facebook pode ser utilizado como um instrumento de accountability política, o caso analisado - o perfil da presidente brasileira no Facebook - não se enquadra nessa definição. Por outro lado, a equipe de comunicação de Dilma Rousseff poderia argumentar que esse não é o objetivo estratégico da página. Nesse caso, porém, deixaria de cumprir um dos princípios básicos da Comunicação Pública, conforme trabalhado na seção 2.3.

Apesar de visualmente bem produzida, a página peca em não publicar conteúdos de cunho informativo e não incentivar a interatividade dos usuários, não atendendo, assim, aos princípios da accountability. Pelas publicações, nota-se que o perfil funciona mais como uma ferramenta de relacionamento da presidente com seu eleitorado do que propriamente como uma ferramenta de accountability.

Nesse sentido, Coleman (2005, p.189) vai além e questiona o que significa para o representante estar conectado aos representados: 
Para os políticos, a conexão é uma rota de consentir e legitimidade, os quais eles consideram como sendo distorcido por mediações de distração, tendenciosas e incontroláveis da agenda pública. Conectar-se é ter acesso direto e sem distorções ao representado, ser melhor compreendido, nutrir o consentimento público. o papel do representado nesta concepção de conectividade [entretanto] permanece como espectadores antes da tela, fechado em uma relação desigual de comunicação com uma elite não confiável.

Concretizar essa conexão entre representante e representados, para Coleman (2005, p.189), exige uma colaboração comunicativa entre ambas as partes e uma perspectiva de ganho mútuo. Isto é, não basta o representante atuar como um emissor, como é o caso da presidente e sua equipe que gerencia o perfil no Facebook, é preciso dar aos usuários/representados o poder de também se tornarem emissores e ouvi-los, interagir com eles.

Apesar de registrar números altos de curtidas, comentários e compartilhamentos, estes ainda são pequenos frente ao total de seguidores. Por exemplo, o post com maior índice de atividade (o agradecimento da presidente ao atingir 460 mil curtidas) foi publicado em maio: 18.478 curtidas, 1.619 comentários e 1.249 compartilhamentos; todavia, isso representa apenas 3\%, 0,26\% e 0,20\% dos seguidores respectivamente. Denota-se que o usuário tem o hábito apenas de curtir o perfil para receber as atualizações no seu feed de notícias ou mesmo somente como forma de apoio à presidente; poucos são aqueles que realmente desempenham alguma atividade (curtir, comentar ou compartilhar ${ }^{5}$ ).

No que tange ao primeiro pilar da accountability, pela natureza do Facebook, seria normal uma maior ênfase no caráter informacional do que no argumentativo (no sentido de explicar decisões tomadas). Porém, nenhum dos dois aspectos foi contemplado na página da presidente: as publicações tinham cunho mais voltado à

${ }^{5}$ Sem entrar no mérito e na discussão da qualidade dessas atividades. 
popularidade de Dilma e ao entretenimento de seus seguidores, em vez de prestar informações e explicações sobre o desempenho e as decisões da chefe do Poder Executivo. O segundo pilar tampouco prevaleceu, o que se notou pela atuação dos usuários foi muito mais no sentido de premiá-la por seu desempenho do que em qualquer momento questioná-la ou puni-la. A possibilidade existe, mas não é posta em prática. Isso se deve muito ao fato já levantado de que é preciso "curtir" a página para receber as atualizações no seu feed de notícias, uma ação carregada de significados positivos de endosso e apoio, o que pode fazer com que uma pessoa que gostaria de acompanhar as publicações com um olhar mais crítico não o faça por não querer curtir a página, dar esse endosso e prestar esse apoio à presidente.

Quanto à transparência, o perfil poderia ser utilizado dessa forma. No entanto, as publicações não remetem a maior abertura do governo, já que são poucas as informações publicadas. Além disso, as informações que são de fato divulgadas passam por uma rigorosa seleção no sentido de impactar positivamente sobre a imagem de Dilma. Não são todas as informações sobre a atuação da presidente e suas políticas públicas que são publicadas, apenas algumas que interessam à equipe. Que transparência é essa? No Facebook, pelo menos, ela não é exercida.

Pode-se dizer que as publicações feitas na página ganham publicidade, uma vez que não só os mais de 600 mil seguidores podem acessá-las, mas também todos os usuários do Facebook, entre eles os cerca de 76 milhões de brasileiros ativos no SRS. Mesmo que seja inferior ao total da população, é um número significativo, já que representa aproximadamente $80 \%$ dos usuários de Internet no país. Dessa forma, o conteúdo publicado no perfil de Dilma Rousseff está disponível a essa camada, ainda que seja de mais fácil acesso aos 
cerca de 604 mil seguidores que recebem as atualizações diretamente em seu feed de notícias.

Ainda, a atuação do perfil da presidente no Facebook remete à ideia levantada por Coleman (2005, p.181) de uma espécie de campanha permanente, ou seja, fundem-se os períodos de governo e campanha em um relacionamento permanente. Talvez por isso que a página de Dilma Rousseff apresente-se mais como uma forma de se relacionar (ainda que com pouca ou sem interação) com o eleitorado do que como um instrumento de accountability. Pode-se afirmar também que esse é o motivo de terem sido apontados conteúdos relativos à campanha eleitoral durante a análise mesmo fora do período oficial.

A tendência é de que cada vez mais os cidadãos tornem-se um júri contínuo, permanente, do desempenho do governo, enquanto os representantes assumem o papel de defensores das suas decisões e buscam conectar-se aos representados através de uma série de ferramentas (COLEMAN, 2005, p.181), entre elas o próprio Facebook. Contudo, ainda prevalece o uso das TICs, o que inclui as mídias sociais, no sentido de reproduzir práticas tradicionais de comunicação, na manutenção da lógica emissor-receptor/produtorconsumidor, em vez de promover a adaptação aos novos meios e o uso de suas potencialidades (COLEMAN, 2005, p.186). Por enquanto, essa foi a realidade constatada no estudo de caso desenvolvido para o presente artigo. Dessa forma, fica a sugestão para pesquisas futuras de insistir na relação entre o Facebook e a accountability e dedicar-se ao estudo de outros casos, na esperança de que novas práticas sejam implementadas para cumprir o potencial dos SRS na comunicação entre representantes e representados. 


\section{Referências}

BARROS, Antonio Teixeira; BERNARDES, Cristiane Brum. Comunicação Pública na Câmara dos Deputados: a divulgação de informações legislativas no Brasil. In: PAULINO, Fernando Oliveira (org.). Lusocomum - Transparência, Governança, Accountability e Comunicação Pública. Brasília: Casa das Musas, 2009, p.118-193.

BERTOT, John C.; JAEGER, Paul T.; GRIMES, Justin M. Using ICTs to create aculture of transparency: E-government and social media as openness and anti-corruption tools for societies. Government Information Quarterly, 27, p.264-271, 2010. Disponível em <www.elsevier.com/locate/govinf> Acesso em: 28 de jun. 2014.

BIJOS, Danilo. Representação Política e Accountability: na Teia das Relações Federativas. Aurora, 5(2), p.81-100, 2012.

BOBBIO, Norberto. Estado, governo, sociedade: Para uma teoria geral da política. 12ed. Rio de Janeiro: Paz e Terra, 2005.

BOYD, D. M.; ELLISON, N. B. Social network sites: Definition, history, and scholarship. Journal of Computer-Mediated Communication, 2007. Disponível em:

<http://jcmc.indiana.edu/vol13/issue1/boyd.ellison.html> Acesso em: 27 de jun. 2012.

CASTELLS, Manuel. A Sociedade em Rede: A Era da Informação. São Paulo: Paz e Terra, 2007.

COLEMAN, Stephen. New mediation and direct representation: reconceptualizing representation in the digital age". New Media \& Society, 7 (2), p. 177-198, 2005.

CONGO, Mariana. Um terço dos brasileiros tem Facebook: País se torna o $2^{\circ}$ em número de usuários. Estadão Online: Blog Radar Tecnológico. São Paulo: 23 de janeiro de 2013. Disponível em: <http://blogs.estadao.com.br/radar-tecnologico/2013/01/23/um-terco-dos-brasileirostem-facebook-pais-se-torna-o-2o-em-numero-de-usuarios/> Acesso em: 09 de jul. 2014.

GOMES, Helton Simões. Brasil é o $2^{\circ}$ país com mais usuários que entram diariamente no Facebook. G1. São Paulo: 12 de setembro de 2013. Disponível em <http://g1.globo.com/tecnologia/noticia/2013/09/brasil-e-o-2-pais-com-mais-usuariosque-entram-diariamente-no-facebook.html> Acesso em: 09 de jul. 2014.

HOOD, Christopher. Transparency in historical perspective. In ; HEALD, David. Transparency: the key to better governance? Oxford: Oxford University Press, 2006, p. 4-23.

KLASTRUP, Lisbeth. Publics for a day? The Affective "Audiences" on Facebook. In: INTERNATIONAL ASSOCIATION FOR MEDIA AND COMMUNICATION RESEARCH (IAMCR) CONFERENCE 2010. Braga: Universidade do Minho, 2010. Disponível em: <http://iamcr.org/iamcr-2010-virtual-paper-room> Acesso em: 15 de mai. 2012.

MIGUEL, Luís Felipe. Impasses da Accountability: Dilemas e Alternativas da Representação Política. Revista de Sociologia e Política, 25, p.25-38, 2005. Disponível em: $<$ http://repositorio.unb.br/browse?type=author\&sort_by=1\&order=ASC\&rpp=20\& etal=1\&value=Miguel\%2C+Luis+Felipe\&offset=20> Acesso em: 02 de jun. 2014.

Accountability em Listas Abertas. Revista de Sociologia e Política, 18(37), p.183-200, 2010. Disponível em:

$<$ http://repositorio.unb.br/browse? type=author\&sort_by=1\&order=ASC\&rpp=20\&etal=1\&value=Miguel\%2C+Luis + Felipe\&offset $=20>$ Acesso em: 02 de jun. 2014.

. Autorização e accountability na representação democrática. In: II coLóQUIO INTERNACIONAL DE TEORIA POLÍTICA. São Paulo: USP, 2012. Disponível em: $<$ http://repositorio.unb.br/browse?type=author\&sort_by=1\&order=ASC\&rpp=20\&etal=1\&value=Miguel\%2C+Luis+Felipe\&offset=20> Acesso em: 02 de jun. 2014. 
O'NEILL, Onora. Transparency and the ethics of communication. In: HOOD, Christopher; HEALD, David (org). Transparency: the key to better governance? Nova York: Oxford University Press, 2006, p.75-90.

PARMEGGIANI, Brenda. A relação dos media tradicionais com as audiências através das redes sociais online: Um estudo de caso da participação dos telespectadores nos programas The Voice, A Voz de Portugal e The Voice Brasil. 2013. 93f. Dissertação (Mestrado em Ciências da Comunicação) - Faculdade de Ciências Humanas e Sociais, Universidade Nova de Lisboa, Lisboa.

PAULINO, Fernando Oliveira. Comunicação, accountability e responsabilidade social no Brasil, Portugal e Espanha. In: PAULINO, Fernando Oliveira (org.). Lusocomum: Transparência, Governança, Accountability e Comunicação Pública. Brasília: Casa das Musas, 2009, p.95-117.

PEW RESEARCH CENTER. Pew Internet and American Life Project: Politics on social networking sites. Washington: Pew Research Center, 2014. Disponível em:

$<$ http://www.pewinternet.org/files/old-

media/Files/Reports/2012/PIP_PoliticalLifeonSocialNetworkingSites.pdf > Acesso em: 03 de jul. 2014.

PRADO, Mônica. Publicidade de utilidade pública no Brasil: algumas reflexões. In: PAULINO, Fernando Oliveira (org.). Lusocomum: Transparência, Governança, Accountability e Comunicação Pública. Brasília: Casa das Musas, 2009, p.195-211.

RECUERO, Raquel. As Redes Sociais na Internet. Porto Alegre: Sulina, 2011.

SCHEDLER, Andreas; DIAMOND, Larry; PLATTNER, Marc F. The self-restraining state: Power and accountability in new democracy. Londres: Lynne Rienner, 1999.

SCHEDLER, Andreas. Conceptualizing accountability. In: SCHEDLER, Andreas; Diamond, Larry; PLATTNER, Marc F. The self-restraining state: Power and accountability in new democracy. Londres: Lynne Rienner, 1999, p. 13-28.

SEEMAAN, Bryan; ROBERTSON, Scott P.; DOUGLAS, Sara; MARUYAMA, Misa. Social Media Supporting Political Deliberation Across Multiple Public Spheres: Towards Depolarization. In: 17th ACM CONFERENCE ON COMPUTER-SUPPORTED COOPERATIVE WORK \& SOCIAL COMPUTING. Baltimore: University of Maryland, 2014.

SOCIAL BAKERS. Facebook Pages Statistics \& Number of Fans. São Francisco: Social Bakers, 2014. Disponível em:

<http://www.socialbakers.com/facebook-pages/society/country/brazil/tag/politics/> Acesso em: 09 de jul. 2014.

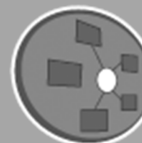

\section{COMPOLITICA} ASSOCIACEAOO BRASILEIRA DE PESQUISADORES EM COMUNICAÇÃO E POLITITICA

Diretoria da Associação/ Director Board

\section{Presidente | President}

Fernando Lattman-Weltman (UERJ)

Vice-Presidente | Vice-President

Arthur Ituassu (PUC-Rio)

Secretária Executiva | Executive Secretary

Kelly Prudêncio (UFPR)

Corpo Editorial / Editorial Board

Editoras-Chefes: | Chief-Editors

Alessandra Aldé (UERJ) \& Maria Helena Weber (UFRGS)

Editores Executivos | Executive Editors

Fernanda Sanglard (UERJ), Rafael Cardoso Sampaio

(UFMG) \& Viktor Chagas (UFF)
A Revista Compolítica é uma revista eletrônica da Associação Brasileira de Pesquisadores em Comunicação e Política

[Revista Compolitica is an electronic journal published by the Brazilian Association of Political Communication Scholars]

Ao citar este artigo, utilize a seguinte referência bibliográfica

[To cite this article, please use the following reference]

PARMEGGIANI, Brenda. Facebook e accountability: um estudo de caso da fanpage da presidente Dilma Rousseff. In: Revista Compolítica 5 (1), 2015 
